\title{
Parental Perceptions of Children's Communicative Development at Stuttering Onset
}

\section{Nan Bernstein Ratner Stacy Silverman University of M aryland, College Park}

There has been clinical speculation that parents of young stuttering children have expectations of their children's communication a bilities that are not well-matched to the children's actual skills. We appraised the language abilities of 15 children close to the onset of stuttering symptoms and 15 age-, sex-, and SES-matched fluent children using an array of standardized tests and spontaneous language sample measures. Parents concurrently completed two parent-report measures of the children's communicative development. Results indicated generally depressed performance on all child speech and language measures by the children who stutter. Parent report was closely attuned to child performance for the stuttering children; parents of nonstuttering children were less accurate in their predictions of children's communicative performance. Implications for clinical advisement to parents of stuttering children are discussed.

KEY WO RDS: stuttering, language development, parents, counseling

T he role of the environment in the onset and evolution of stuttering symptoms continues to generate debate. Although there is little current research literature to suggest that parental beliefs or behaviors differentiate families in which children stutter from those in which children do not (Yairi, 1997), clinical advisement continues to emphasize the possible role of parental attitudes and behaviors in shaping stuttering behavior in childhood (e.g., Conture \& Melnick, 1999; Gottwald \& Starkweather, 1999; Guitar, 1998; Shapiro, 1999; Starkweather, Gottwald, \& Halfond, 1993; Wall \& Myers, 1995).

Yairi (1997) summarizes much of the available literature on the beliefs of parents whose children stutter. It is, in general, an aging body of work, most of which targeted rather global measures of parental attitude and behavior. Older research suggested that some parents of stuttering children held unrealistic expectations of them: Darley (1955) found that mothers of children who stutter believed that their children were not achieving as expected in speech/language development or in school. Goldman and Shames (1964) asked parents to predict how well their child would perform on a motor coordination task and a language sample task (story telling). Parents of children who stutter, most notably fathers, tended to overestimate their child's performance relativeto actual outcomes. However, Quarrington, Seligman, and Kosower (1969) failed to replicate this finding. Instead, mothers of children who stuttered set lower goals for their children than parents of the comparison group. 
Inappropriate parental expectations could be expected to demonstrate themselves in behaviors that are either fluency-disrupting or nonconducive to recovery from stuttering. Clinical advisement to parents appears to reflect a wide range of interpretations of existing data and clinical impressions. In particular, the linguistic environment of the child who stutters has been a frequent target of clinical comment. Guitar (1998) lists "stressful adult speech models" (defined by speech rate, polysyllabic vocabulary, complex syntax, and/or a multilingual environment) as factors that may trigger or maintain dysfluency in children. Tothis, headds stressful speaking situations, including frequent interruptions, frequent questioning, and other behaviors that can impair fluency potential in children. Of the items on this list, speech rate and interruptions have been shown in some studies to distinguish between parent-child interactions in which fluency waxes and wanes (Conture, 1997; Ratner, 1997). (But see Nippol d \& Rudzinzki, 1995 for a critique of this literature and Gottwald, 1999 for a response.) Evidence for the relationship among structural characteristics of parental language models, Ianguage expectations, and children's fluency has been sparser, although Starkweather (1997) provides two "tracks" of early childhood stuttering in which environmental responses to children's language abilities may be inappropriate. The first track consists of children whose language capacity is too limited to meet typical demands for communication placed by theenvironment (cf. parents); the second consists of children whose language appears adequate, but whose parents inappropriately encourage ever-increasing levels of sophistication in the child's language efforts. Starkweather (1997 and elsewhere) cites an unpublished manuscript by Amster (1989) as evidence that some children who stutter experience an environment of "language overstimulation." In some cases, such overstimulation may reflect the parents' desire to reinforce sophisticated language use on the part of at-risk children. "When children who are advanced in their speech development produce forms that are more adult than is expected for their age, parents typically react with considerable pleasure. Thoughts of Harvard begin to dance in their heads, and this delight in their child's performance is likely to be translated into parental reactions, both verbal and nonverbal, that reinforces the child for these moreadult productions" (Starkweather, 1997, p. 267).

A number of years ago, Van Riper (1973) noted that some parents of young stuttering children "reject perfectly good simplesentences and rephrase them in highly complex forms, then insist that the child say them their way" (p. 382). He continued by noting that "often they overpraise and overencourage the child once he begins to talk and demand more and more verbal facility. Many times we have been able to eliminate the stuttering merely by reducing these parental expectations and demands." Relatively straightforward counseling to parents that they "use short simple utterances" (Stuttering Foundation of America, video, 1993) when speaking to stuttering children, that they "simplify [sic], soften and slow the daily speech model to which the child is exposed" (Shapiro, 1999), and avoid "vocabulary far above [the] child's level [and] advanced levels of syntax" (Guitar, 1998) is relatively common dinical advisement.

It is striking that, given the clinical emphasis on modifying linguistic demands in the environment of stuttering children, relatively little research has examined specific parental beliefs about child language in parents of children who stutter. There has been some effort to describe specific behavioral characteristics of interactions between stuttering children and their parents. A large proportion of the existing data addresses speech rateand other temporal variables (e.g., Kelly, 1994; Kelly \& Conture, 1992; Meyers \& F reeman, 1985a, 1985b; Stephenson-Opsal \& Ratner, 1988), with lesser attention paid to linguistic characteristics of parental speech to stuttering children (e.g., Langlois, Hanrahan, \& I nouye, 1986) and nonlinguistic conversational patterns (e.g., LaSalle \& Conture, 1991). Yairi (1997) notes that "the current body of data on parents' speech is small in terms of the number and scope of studies completed" (p. 41). Guitar (1998) asks, "What do we know about the speech and language of parents of stutterers? Unfortunately, very little" (p. 66). As Conture (1997) notes, "most clinicians are uncertain about how parental beliefs, feelings, or behavior relate to childhood stuttering. Simply put, a great deal more needs to be known about how a variety of parental variables do or do not relate to the cause, exacerbation, or maintenance of childhood stuttering" (p. 244). Yairi (1997) concurs: "The research literature pertaining to the home environments of children who stutter is extensive but spread over many areas. As a result, some areas have been barely examined" (p. 41).

In sum, there is no shortage of clinical advisement that either subtly or overtly suggests that parents of children who stutter do not have realistic expectations of their children's linguistic capacity. Given the dearth of research that has specifically targeted parent beliefs that might affect their roles in the precipitation or maintenance of stuttering, we undertook to investigate whether parents of children who have recently begun to stutter differ in beliefs about their children's communicative development from parents of children who do not stutter. This work is not concerned with validating clinical impressions of atypical levels of linguistic demand in the actual speech of parents of stuttering children, for which research support is also rather sparse. Rather, we ask whether parents of children who stutter understand the current level of their children's communicative development. A parent who cannot accurately judge 
the communicative proficiency of a young child might be expected to impose unrealistic models or expectations on thechild. Conversely, parents whoappear well-attuned tochildren's linguistic devel opment should beexpected to fine-tunetheir style of interaction to them in appropriate ways, because children's linguistic performance has been shown to be a potent predictor of modifications in input to them (Rondal, 1978; Snow, 1995; Sokol ov, 1993).

\section{Method}

\section{Subjects}

This report derives from a larger study of 15 children within 4 months of stuttering onset and their parents. Children who stutter were referred by parents, pediatricians, and local speech-language pathologists because of concerns about fluency. After parental interview, only children whose onset of stuttering symptoms could be ascertained to be within 4 months of intake were included for the study reported here (mean elapsed time since onset of symptoms: 2.53 mos.). These children had a mean stuttering frequency (as derived from spontaneous language sampling described below) of $9.11 \%$ stuttered words, a category that included sound, syllable, and monosyllabic whole-word repetition, blocks, prolongations, and broken words. Range of stuttering in spontaneous speech was wide, with a minimum of $3 \%$ stuttered words (SW) and a maximum of $25.5 \%$ SW. Mean age of stuttering children was 35 mos. (range: 2747 mos.); 12 were boys and 3 were girls. None of the children had suspected delays in other areas of speech/ language devel opment. All children and parents spoke a standard dialect of American English and came from middle- to upper-middle-class families (mean level of maternal education: $16 \mathrm{yrs}$ ).

After the 15 stuttering children were enrolled, each was sex-, SES-, and age-matched (within 3 months CA) by recruitment through the same posting sites used to recruit the stuttering children, using a differently formatted advertisement calling for child subjects in a study of normal language acquisition. Mean age of the nonstuttering children was 35.67 mos. (range: 27-47 mos.). Each matched cohort of children included 2 African American children, 1 child of mixed racial ancestry, and 2 children from single-parent (mother-only) households. One stuttering child came from a household in which the mother currently stuttered; no other children had parents who stutter, although some of the stuttering children had other relatives who stutter.

The final sample of comparison children and parents did not differ significantly from thestuttering children or parents on measures of child CA or parental SES (as measured by maternal education) and was matched for gender. No child in the study, regardless of group, had ever been seen previously for a speech or language evaluation.

\section{Tasks \\ Child Measures}

As part of a larger battery of standardized and experimental measures, all children completed the following measures:

Goldman-Fristoe Test of Articulation (Goldman \& Fristoe, 1987)

Peabody Picture Vocabulary Test-R (Dunn \& Dunn, 1981)

Expressive One-Word Vocabulary Test-R (Gardner, 1985)

CELF-Preschool, Word Structure and Linguistic Concepts subtests (Wiig, Secord, \& Semel, 1992)

Expressive spontaneous language samples were taken from parent-child interaction using a standard set of toys. This sample provided the basis for calculations of Mean Length of Utterance (MLU), Type-Token Ratio (TTR), and Lexical Rarity (Beals \& Tabors, 1995).

Children were individually tested in a sound-treated observation suite; both audio and video recordings of sessions were made. All formal testing was done by the first author. Language samples were transcribed into Codes for the Human Analysis of Transcripts (CHAT) (MacWhinney, 1995; Ratner, Rooney, \& MacWhinney, 1996) by two graduate assistants. Reliability of transcription was assessed by duplicate coding of morphological and fluency tiers for $20 \%$ of thestuttering children's files. Coding reliability ranged from .88 to .95. Disagreements on coding were resolved by consensus of the first author and two coders to yield final files.

\section{Data Reduction: Transcripts}

F or spontaneous language measures, a standard subset of the middle 50 consecutive utterances that were nonimitative and contained a subject-predicate sequence wereselected. Computerized LanguageAnalysis (CLAN) programs (MacWhinney, 1995) were used to compute Mean Length of Analysis (MLA), Type-Token Ratio (TTR), and fluency (FLUCALC; Ratner et al., 1996). The CLAN frequency-count (FREQ) program was adjusted to eliminate high-frequency words of English in transcripts (Beals \& Tabors, 1995), yielding themeasures of lexical rarity in child language transcripts.

\section{Treatment of Standardized Test Results}

Stuttering onset occurred for many of the stuttering children beforeage 3;0 (years;months). Few standardized 
tests provide normative data for children spanning the ages between 2 and 3 years. In particular, the CE LF-P's norms begin at age 3;0. We wanted to appraise morphological ability and language comprehension, but could find no tests of equivalent structure with norms applicable to the 24 month and upward age range. Thus, CELF-P values were converted into percentile scores expected for children at CA 36 mos. when children were younger than 3;0. In this case, 7 stuttering children and their comparison peers fell bel ow this threshold and had scores converted. All other measures we selected had norms that encompassed the age span 2;0 to 3;11-the maximum CA for any child subject.

\section{Parent Measures}

Parents completed the following assessment measures:

Speech and Language Assessment Scale (SLAS) (Hadley \& Rice, 1993)

MacArthur Communication Devel opment I nventory (CDI )-Toddler (Fenson et al., 1993)

Because these measures are not as commonly empl oyed as the standardized child measures, a few words of description are provided here. The SLAS is a global measure of children's communicative devel opment which uses a 7-point Likert scale to appraise adult ratings of children on statements such as "My child's ability to say sentences clearly enough to be understood by strangers is...," "My child's ability to use the proper words when talking to others is...." No items on the SLAS specifically target fluency, and the majority of items prompt judgment of language comprehension and production, as well as articulation. The MacArthur CDI has gained increasing visibility in clinical and research assessment of child language. It asks parents to identify the expressive lexicon used by the child and to select those grammatical constructions more typical of the child's utterances. Its validity as a reflection of the child's actual expressive language performance is increasingly recognized (Robinson \& Mervis, 1999; Tomasello \& Mervis, 1994). Both mothers and fathers of both groups of children completed the SLAS and CDI separately.

\section{Results \\ Parental Report Measures}

Parental responses are displayed for mothers and fathers for each group for each of the two assessment measures. Not all children's parents provided usable data. Fathers were not availablefor interview in a number of families or did not complete forms during the assessment despite encouragement. Additional forms from some mothers and fathers were not used because parents "straight-lined" responses (e.g., wrote "he knows all this," despite our requests for item-by-item responses) or did not complete the entire form. In theend, usable data were provided by 11 of the 15 mothers of stuttering children, 12 of the 15 mothers of nonstuttering children, 8 of the 15 fathers of stuttering children, and 9 of the 15 fathers of nonstuttering children. As can be seen in Figures 1 and 2, parents of children who stutter provided significantly lower estimates of their children's communicative development, both globally (SLAS values) and specifically (CDI lexicon and grammar subscales).

For the SLAS, mothers of stuttering children gave an average score of 4.45 out of 7 possible points, whereas those of nonstuttering children rated them at 5.69 out of 7 ( $t=-2.95, p<.007$ ). Fathers demonstrated a similar profile, rating stuttering children at an average of 4.209 out of 7 and nonstuttering children at 5.766 out of 7 ( $\mathrm{t}=-3.125, \mathrm{p}<.007$ ). This pattern was replicated in parental $C D I$ reports, where the value entered into the comparison was proportion of credited items. Mothers

Figure 1. Parental report on the CDI for stuttering and nonstuttering children.

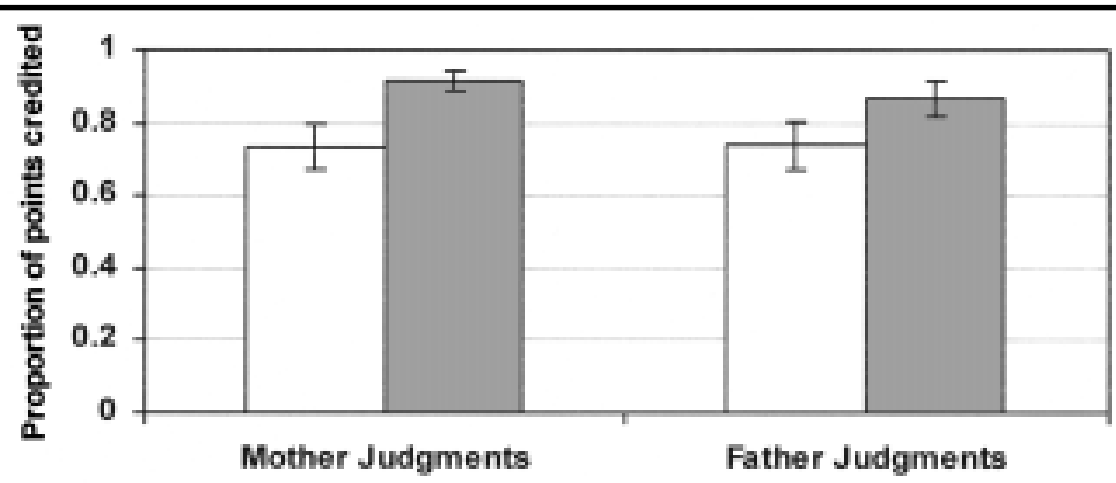

Children who stutter $\square$ Children who do not stutter 
Figure 2. Parental report on the SLA S for stuttering and nonstuttering children.

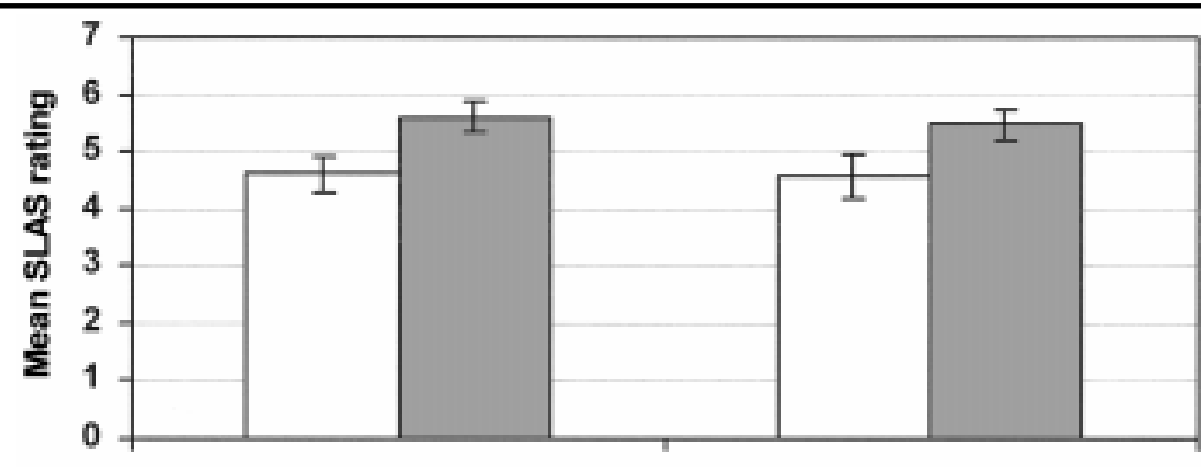

Mother Judgments

Father Judgments

Children who stutter $\square$ Children who do not stutter

of stuttering children provided average CDI ratings of .692 , whereas those of nonstuttering children provided markedly higher scores of .941 ( $t=-3.111, p<.006)$. Fathers provided similar rating patterns. Fathers of stuttering children gave mean ratings of .656 , whereas those of nonstuttering children provided an average rating of $.89(t=-2.51, p<.027)$.

\section{Children's Performance on the Standardized Tests}

Stuttering children performed within normal limits on virtually all specific assessments and as a group. However, the stuttering children consistently scored at a lower mean level of performance than the comparison children. Stuttering children did not, as a group, achieve a higher mean score than nonstuttering children on any of the assessment measures employed in this study. Figure 3 displays the results of formal testing in percentile scores. NCSS 2000 (Hintze, 1999) was used to compute comparisons. On some measures, equality of variances could not be assumed; to maintain consistency, all comparisons of child performance were computed using nonparametric tests, with conversion to $Z$ scores to correct for ties (Hintze, 1999). Alpha was set at .05 (two-tailed) for each comparison.

Differences between the two groups of children were significant, with lowered performance by the stuttering children, for the EOWVT (mean score for children who stutter $[C W S]=69.6$; mean score for children who do not stutter [CWDNS] = 84; Mann-Whitney Z 1.7054, $p$ $=.04)$ and for the CELF-P Linguistic Concepts subtest (mean score for CWS $=48.31$; mean score for CWDNS $=$ 75.3; Mann-Whitney $Z=-2.2498, p=.01$ ). No other comparisons reached significance, although stuttering children performed more poorly on each measure. For the

Figure 3. Standardized test performance of stuttering and nonstuttering children.

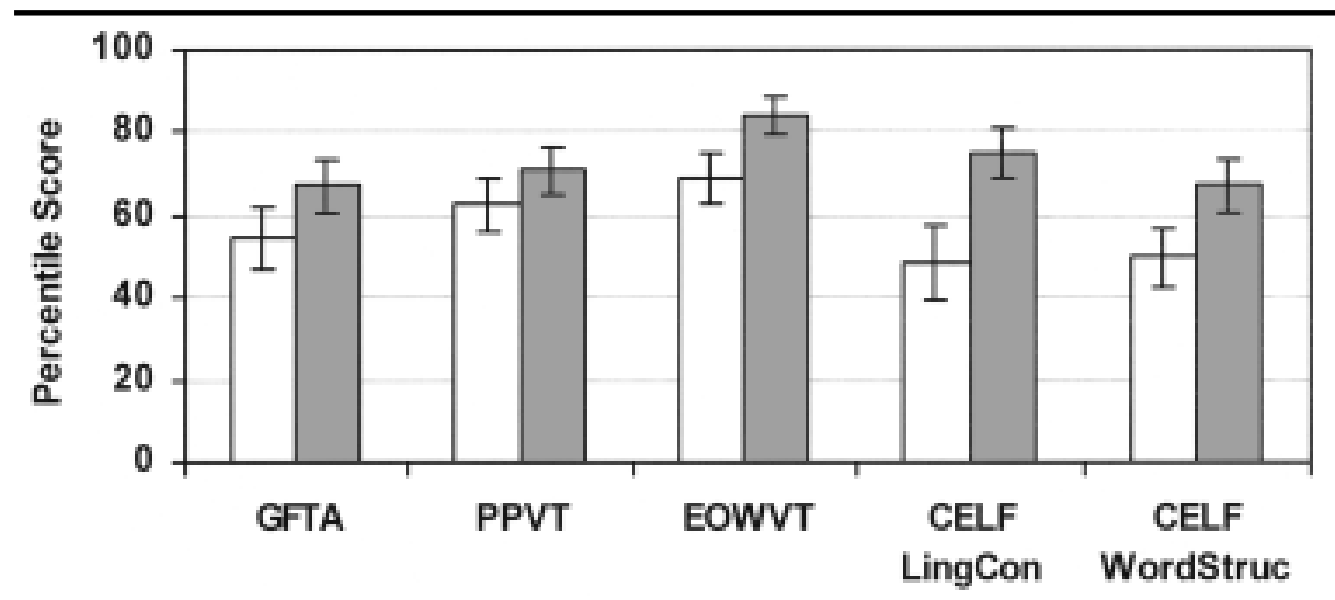

Children who stutter $\square$ Children who do not stutter 
GFTA, average score for CWS was 54.2; for CWDNS, average score was 67.1. For the PPVT, average score for CWS was 62.7, whereas CWDNS achieved an average percentile score of 71.1. Finally, average performance on the CELF-P Word Structure subtest was at the 49.8th percentile for CWS and the 67.3rd percentile for CWDNS.

Unlike the formal language measures, where a single score on a limited task cannot identify impairment, it is theoretically possible to make an extremely cursory judgment of clinical impairment in articulation using the GFTA. Because concurrent impairment of phonology and fluency has been a specific focus of research (e.g., Louko, Edwards, \& Conture, 1990), we note that 4 stuttering children achieved percentile scores bel ow the $25^{\text {th }}$ percentile on this measure, whereas only 1 nonstuttering child did. There is no universally accepted cut-off for assignment as clinically impaired; however, if a score bel ow the $25^{\text {th }}$ percentile were chosen, slightly less than $27 \%$ of these children would have been identified as having concurrent phonological impairment-a level much lower than those seen in some other studies of young stuttering children.

\section{Spontaneous Language Measures}

Spontaneous language measures showed a profile of performance similar to that of formal test findings.
Measures taken of spontaneous language included mean length of utterance computed in words, morphemes, and syllables; type-token ratio; and mean frequency of rare lexical items in thestandard 50-utterance sample (Beals $\&$ Tabors, 1995). Figure 4 displays results of spontaneous language analyses.

For no measures did the stuttering children, as a group, achieve higher average scores than did their fluent peers, although mean TTR values were identical for the two groups. MLU was lower for stuttering children, whether calculated using the standard morphological parsing or using length of utterance as measured by words or syllables, and approached significance for each measure. Use of rare words was significantly different between the two groups (Mann-Whitney $Z=2.4551, p=$ .01 ), with the stuttering children using significantly fewer rare lexical items in their conversational speech than the nonstuttering children.

\section{Relationship Between Parental Judgments and Children's Test Performance}

Pearson product moment correlations were run between individual parental judgments and the parents' child's actual performance. Correlation matrices were generated for mothers and fathers separately for each of thetwo parent-report measures, for each group. Because

Figure 4. Spontaneous language sample results for stuttering and nonstuttering children.
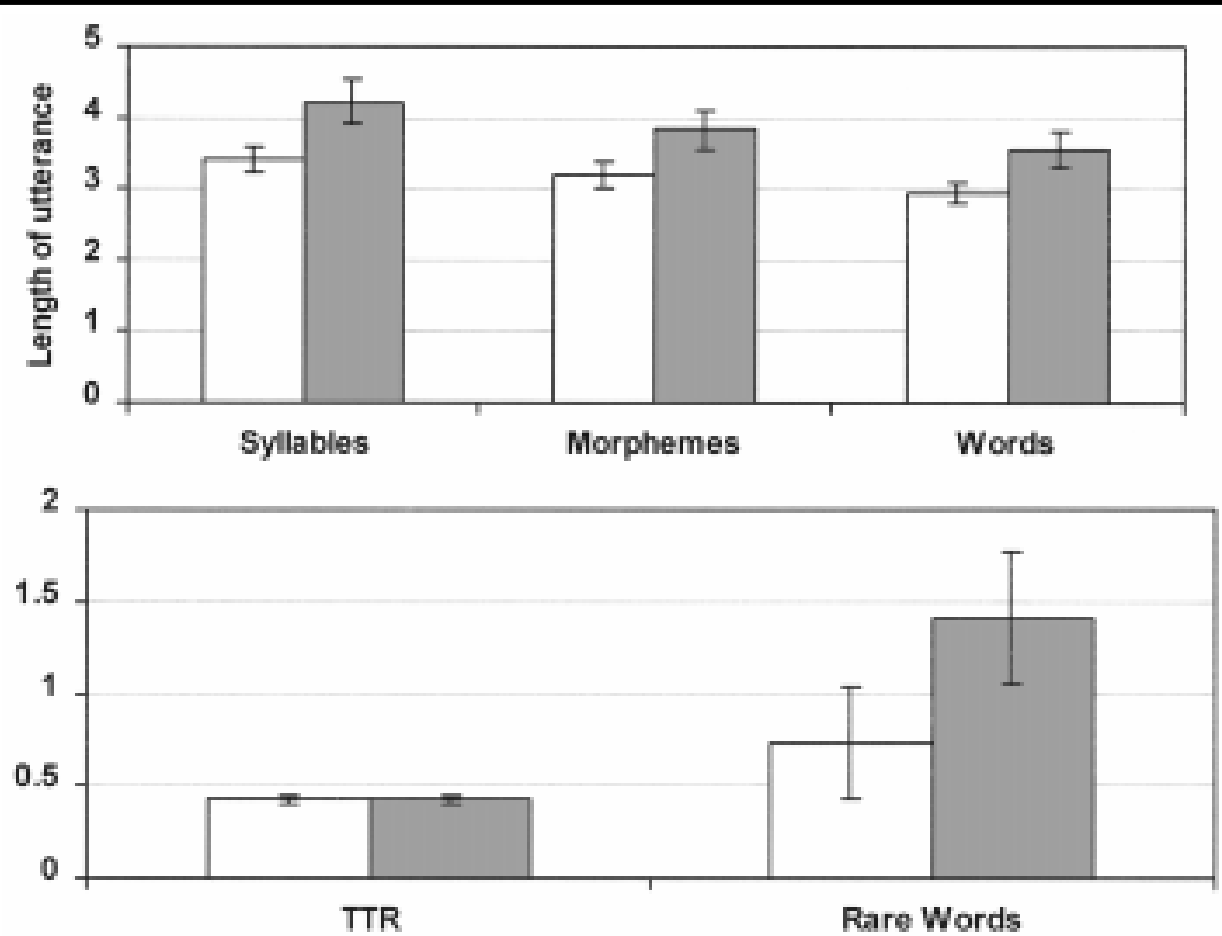

Children who stutter $\square$ Children who do not stutter 
of the large number of correlations generated, al pha was reduced to .0125 for the hypothesis that any single parent group (mothers of CWS and CWDNS, fathers of CWS and CWDNS) showed accurate judgment of children's language performance. Matrices are provided in the Appendix. Because $p$ was set conservatively, few correlations achieved statistical significance. However, in general, parents of stuttering children provided SLAS and CDI ratings that correlated much more highly with children's performance on the standardized tests and spontaneous language analysis than did parents' ratings of nonstuttering children. For fathers of stuttering children, SLAS scores approached significant correlation with child performance on the GFTA $(r=.8146, p=$ $.0138)$, the EOWVT-R $(r=.7869, p=.0205)$, and the CE LF-P Word Structure scale $(r=.7691, p=.0257)$. All correlations between the stuttering children's paternal SLAS scores and child performance were positive, with the exception of SLAS-TTR. CDI scores showed a complementary pattern, with significant correlations between paternal report and PPVT-R scores $(r=.8845, p=.0032)$, and correlations with all three MLU values that approached significance.

For mothers of stuttering children, the SLAS score was also significantly correlated with the CELF-P Word Structure Scale $(r=.7945, p=.0035)$ and all MLU calculations $(r$ range $=.8871-.7941$, p range $=.0003-.0035$ ). Maternal SLAS scores also approached significant correlation with GFTA performance $(r=.6731, p=.0232)$. Similar to paternal results, SLAS-TTR correlations were nonsignificant, but in a negative direction. Maternal CDI scores were highly correlated only with the PPVT-R ( $r=$ $.6300, p=.0378$ ) but were universally positive and fairly strong, in parallel with paternal results.

Despite the fact that parents of nonstuttering children provided higher overall ratings for their children on both the SLAS and CDI, correlations between parental judgments of the nonstuttering children's communicative abilities and their actual performance results were much weaker, and a number of negative correlations were observed, suggesting parental impressions less finely tuned to their children's development. For paternal SLAS, nosignificant correlations were observed with child speech and language performance, and negative correlations were observed for SLASPPVT-R, SLAS-CELFP-LC, and SLAS-TTR. F or paternal CDI, no significant correlations were observed with child performance, with negative correlations obtained for CDI-EOWVT-R, CDI-CELFP-LC, and CDIMLU/CDI-MLU-W.

Maternal judgments of nonstuttering children were more uniformly positively correlated with their children's performance, although only one correlation approaching significance was observed (SLAS-GFTA $r=.6901, p=$
.0129). Maternal SLAS was negatively correlated with childTTR; maternal CDI was negatively correlated with the GFTA and TTR.

There were no statistically significant differences between the groups of mothers and fathers on either measure. However, to appraise whether mothers and fathers of individual stuttering children differed in the degree to which they agreed in their assessment of children's communicative development, correlations were computed for maternal and paternal SLAS and for maternal and paternal CDI for each group. Alpha was set at $p=.05$ for this analysis. Parents of stuttering children were much more highly in agreement on their judgments of their child's current communicative abilities than were parents of nonstuttering children. Parental SLAS judgments for stuttering children were correlated at $r=.8867, p<.00$, whereas those for nonstuttering children were much less highly correlated ( $r=$ .3077, ns). F or the CDI , maternal and paternal judgments of stuttering children werecorrelated at $r=.6519, p=.04$, whereas parental judgments of thenonstuttering children were again more poorly correlated $(r=.1522, n s)$.

\section{$\overline{\text { Discussion }}$}

Appraisal of parental belief systems is one approach to the evaluation of the claim that parents of stuttering children establish a communicative environment for children that inadvertently may stress speech or language capacities, resulting in nonfluency. Parental questionnaires measure what parents think, rather than what they do-an obvious limitation. However, as a starting point, comparison of parental judgments with children's actual linguistic performance enables us to appraise how closely attuned parents appear to be to their children's abilities at the time that stuttering first emerges.

We first turn our attention tothe parental judgments of the children. Ratings of stuttering children fall significantly short of those provided by the parents of nonstuttering children, but such results cannot be interpreted independent of the children's actual performance because they mirror in part the stuttering children's lowered performance on both standard testing and language-sample analysis. The generally depressed ratings provided by parents of stuttering children show no evidence that parents of children at stuttering onset view them as linguistically precocious, at least not as a group. Conversely, neither are they viewed as communicatively inadequate, and they are not. Both general child performance and parental ratings were at a level we might construe to be "average" to "above average" (near the $50^{\text {th }}$ percentile, or slightly above it). 
We note that individual parents' scores correlate rather well with the actual performance of their stuttering children on a wide array of standardized tests and on spontaneous language measures. Although not a focus of the current study, we note that parental Ianguage behavior is usually finely tuned to children's performance (Gleason, 1979; Perlmann, 1984; Rondal, 1978; Snow, 1995), thus suggesting that our study parents would act on their questionnaire responses to provide children with appropriately modified input. The questionnaire ratings offered by the parents of nonstuttering children are much less strongly correlated with actual child performance. Such results diminish thelikel ihood that, for this sample at least, parents of stuttering children hold unrealistically high (or low) expectations of what their children understand, what they can say, or how well they can say it.

Because stress could be induced in a household where parents held widely differing views of their child's devel opment, correlations between mothers' and fathers' judgments were also computed. Parents of stuttering children were highly in agreement on such measures, suggesting that discrepant perceptions were not a likely source of stress in thesestuttering children's households. It is possible that parental judgments were tuned by awareness of the child's stuttering problem that in turn caused a heightened attention to the child's overall communicative status; this hypothesis is strengthened by the generally less accurate performance of parents of nonstuttering children, who expressed no concerns about their children's communicative skills, in predicting their children's language performance. However, if concern about the child's stuttering attuned the parents to the child's other communicative abilities, such tuning occurred very rapidly after the onset of symptoms, given the timing of this study. Certainly, by thetimesuch parents reach the speech-language pathologist's office, there is reason to believe that they have a fairly accurate appreciation of their children's current level of linguistic development.

We next address the language performance demonstrated by the stuttering children in this study. Dispute about the language proficiency of stuttering children and its possible role in the evol ution and maintenance of stuttering symptoms is longstanding (Nippold, 1990; Ratner, 1995, 1997). Although none of the stuttering children in this study demonstrated clinically relevant language delay across enough measures to justify classification as impaired, there were observable differences, some significant, between the performance of stuttering and nonstuttering children in this study. We note that this study used more concurrent measures of linguistic performance than has been typical in past studies (see Nippold, 1990 for review) and that measures were selected to tap a broad array of comprehension and production skills. In addition, an array of spontaneous language measures was administered in conjunction with the formal tests. Such a protocol makes any potential differences that might exist in linguistic ability between stuttering and nonstuttering children more likely to emerge. The specific language results obtained are not the primary focus of the current discussion, however, and we shall not address them extensively here. We note only that, in this small sample of children examined close to the onset of stuttering symptoms, speech and language abilities, while firmly within normal limits, do not appear to be as advanced as those of comparison children of the same age, sex, and SES. Thus, it is plausible, at first blush, that these children could more easily encounter communicative demands exceeding their ability to generate fluent speech.

The use of parental questionnaires to augment or replace formal assessment for very young children has come under increasing investigation, with mounting evidence that the CDI, in particular, is a very valid measure of children's devel opment, correlating well with concurrent or sequential assessment of typically and atypically developing children's actual performance on spontaneous language measures (Robinson \& Mervis, 1998; Thal, O'Hanlon, Clemmons, \& Fralin, 1999; Tomasello\& Mervis, 1994). For the stuttering children in this study, the CDI also showed good agreement with standardized and spontaneous language performance, with slightly poorer agreement with performance for nonstuttering children. In general, the CDI seems to correlate best with lexical and MLU measures-something that is not particularly surprising, given its emphasis on expressive vocabulary and sentence structure patterns observed in children's language. We are not aware of any published formal analysis of the SLAS's specific strengths in identifying target areas of performance. In this study, SLAS scores tended to have highest correlation with the GFTA, suggesting perhaps that global articulation ability washes over to general appraisal of "communicative maturity" and "speaking well." In this regard, the recent longitudinal study by J ohnson et al. (1999) suggests that parents and professionals appear to identify articulation proficiency (and lack of it) more aggressively in young children than they do language ability. The SLAS also has a small number of specific questions that target speech intelligibility and pronunciation, increasing likelihood of high correlation with GFTA performance.

Only a handful of studies have targeted fathers' ratings of children's communicative development, whether in typically developing children (Perlmann \& Gleason, 1993) or in the families of stuttering children (Kelly, 1994). It is notable that fathers of stuttering children appeared best able to judge their children's communicative performance through SLAS questions, with multiplesignificant correlations across a wide array of performance domains. We do note that consistent with other studies of fathers' 
linguistic interactions with children (Perlmann \& Gleason, 1993; Ratner, 1988) fathers in both groups tended to provide nonsignificantly higher ratings of children's language skills than did the children's mothers-a possible sign of relatively greater linguistic demand by fathers in general. Fathers seem to credit their children with greater knowl edge and do provide more advanced input model s to children than do mothers. As noted elsewhere (Ratner, 1997), the fact that fathers do, in fact, create a generally more challenging communicative environment for children than do mothers should urge caution in clinical interpretation of isolated examples of paternal language use that might appear atypical when weighed against more frequently observed maternal interactions. Such behaviors are less likely to be clinically relevant than might otherwise be supposed.

It is not the intent of this paper to suggest that parent questionnaires are the best way to evaluate the potential contributions of adult beliefs or behaviors to the onset and maintenance of stuttering. However, they provide a useful first approach to estimating the potential strength of such contributions. The obvious companion analysis that must be done is to compare the degree to which parents of stuttering and nonstuttering children adjust their child-directed speech (CDS) to the child's current level of linguistic performance ("fine-tuning"), and that is what we are currently doing. Differences between the levels of fine-tuning seen in CDS to stuttering and nonstuttering children near symptom onset would strengthen the advisability of recommendations to parents to simplify language addressed to stuttering children, whereas no observable differences would weaken claims for the merits of such counseling or its likely effects on fluency.

Controversy about the efficacy of "indirect" intervention on children's stuttering is longstanding (Attanasio, 1999). Clearly, claims about the efficacy of intervention can be evaluated through carefully designed intervention efficacy research (Ingham \& Riley, 1998). However, the basic logic through which individual therapy components enter a regimen is also a critical issue in the effort to hone the efficacy of our interventions. Because many therapies are quite multifaceted and involve complex combinations of direct and indirect manipulations of behavior, it would appear critical to isolate those components most likely to achieve efficacious effects and to remove those for which theoretical and practical support are weaker.

The assumption that parental language models or expectations play a negative role in the etiology and maintenance of some children's stuttering is not trivial, even if modification seems to be, at worst, nonefficacious in treating the child's fluency disorder. The complexity of parental language input (Murray, J ohnson, \& Peters, 1990), the variety of lexical exemplars in the input
(Huttenlocher, Haight, Bryk, Seltzer, \& Lyons, 1991), the frequency of parental verbal interaction with children, and parental tendency to recast and request imitation are all behaviors that have shown robust correlations with advances in children's linguistic development (see Huttenlocher, 1998 and Snow, 1986 for review). The last behavior on this list, parental recasting, seems to be a behavior remarkably similar to Van Riper's (1973) cautionary example of poor parental conversational gambits, and it may be worth noting that a recast "gap" (a lower proportional incidence of parental recasting) has been targeted in speech to slow language learners by Nelson, Welsh, Camarata, Butkovsky, and Camerata (1995) and Conti-Ramsden, Hutcheson, and Grove (1995). This fact prompted Snow (1995) to speculatethat their relatively diminished presence in the input might compound the effects of SLI. Thus, it is exactly those behaviors targeted for reduction in the speech to stuttering children that appear to be statistically rel evant for the strengthening of language skills in other populations of children under study.

The stuttering children in this study, and in some others (e.g., Ryan, 1992; St. Louis \& Hinzman, 1988), demonstrated slightly depressed languageabilities when compared to fluent peers. In the absence of a diagnosis of stuttering, children with depressed linguistic profiles would becandi dates for parental advisement to increase the frequency of behaviors being targeted for reduction in stuttering. Because of this, it appears to be especially critical that we improve our understanding of the relationship among parental linguistic models, linguistic demands, and stuttering. It may well be that we can validate a negative relationship between parental language complexity, or parental interaction style, and fluency. However, in the absence of such validation, we run the very real risk of depressing linguistic input to children for whom language skills are al ready somewhat fragile. Such advisement would not be benign.

In sum, this study represents a first attempt to understand how well parents of young children near stuttering onset understand their children's current level of speech and language devel opment. Our initial impressions are that such parents are quite well-attuned to what their children understand, their expressive lexical and syntactic abilities, and their phonological development. Such profiles would presume that they provide their children with appropriately fine-tuned input, and our current ongoing research explores this assumption.

\section{Acknowledgments}

We wish to thank the families and children who participated in this study and to acknowledge the hel $p$ of Carrie Bain, Mary Kate Lotto, and Stephanie Miles in data collection and analysis. 


\section{References}

Amster, B. (1989). Case studies in languagestimulation and stuttering. Paper presented at the annual convention of the American Speech-Language-Hearing Association, St. Louis, MO.

Attanasio, J . (1999). Treatment of stuttering: Some reflections. In M. Onsl ow \& A. Packman (Eds.), The handbook of early stuttering intervention (pp. 189-204). San Diego: Singular.

Beals \& Tabors, P. (1995). Arboretum, bureaucratic and carbohydrates: Preschoolers' exposure to rare vocabulary at home. First Language, 15, 57-76.

Conti-Ramsden, G., Hutcheson, G., \& Grove, J . (1995). Contingency and breakdown: Children with SLI and their conversations with mothers and fathers. J ournal of Speech and Hearing Research, 38, 1290-1302.

Conture, E. (1997). Evaluating childhood stuttering. In R. Curlee \& G. Siegel (E ds.), Nature and treatment of stuttering: New directions (2nd ed., pp.239-256). Boston: Allyn \& Bacon.

Conture, E., \& Melnick, K. (1999). The parent-child group approach to stuttering in preschool children. In M. Onslow $\&$ A. Packman (E ds.), The handbook of early stuttering intervention (pp. 17-52). San Diego: Singular.

Darley, F. (1955). The relationship of parental attitudes and adjustments to the development of stuttering. In W. J ohnson (E d.), Stuttering in children and adults. Minne apolis: University of Minnesota Press.

Dunn, L., \& Dunn, L. (1981). Peabody Picture Vocabulary Test-Revised. Circle Pines, MN : American Guidance Service.

Fenson, L., Dale, P., Reznick, J ., Thal, D., Bates, E., Hartung, J ., Pethick, S., \& Reilly, J . (1993). The MacArthur Communicative Devel opmental I nventories. San Diego: Singular Press.

Gardner, M. (1985) Expressive One Word Vocabulary TestRevised. Novato, CA: Academic Therapy Publications.

Gleason, J . (1979). Sex differences in the language of children and parents. In O. Garnica \& M. King (Eds.), Language, children and society (pp. 149-158). Oxford, U.K.: Pergamon Press.

Goldman, R., \& Shames, G. (1964). Comparison of the goals that parents of stutterers and nonstutterers set for their children. J ournal of Speech and Hearing Disorders, 29, 381-389.

Goldman, R., \& Fristoe, M. (1987). Goldman-F ristoeTest of Articulation. Circle Pines, MN: American Guidance Service.

Gottwald, S. (1999). Family communication patterns and stuttering devel opment: An analysis of the research literature. In N. Bernstein Ratner \& E. C. Healey (Eds.), Stuttering research and practice: Bridging the gap (175192). Mahwah, NJ : Erlbaum.

Gottwald, S., \& Starkweather, C. W. (1999). Stuttering prevention and early intervention: A multi-process approach. In M. Onslow \& A. Packman (Eds.), The handbook of early stuttering intervention (pp. 53-82). San Diego: Singular.

Guitar, B. (1998). Stuttering: An integrated approach to its nature and treatment (2nd ed.). Baltimore: Williams \& Wilkins.

Hadley, P., \& Rice, M. (1993). Parental judgments of preschoolers' speech and language development: A resource for assessment and IEP planning. Seminars in Speech and Language, 14, 278-288.

Hintze, J . (1999). NCS 2000. Kaysville, UT: NCSS.

Huttenlocher, J . (1998). Language input and language growth. Preventive Medicine, 27, 195-199.

Huttenlocher, J ., Haight, W., Bryk, A., Seltzer, M., \& Lyons, T. (1991). Early vocabulary growth: Relation to language input and gender. Devel opmental Psychology, 27, 236-248.

Ingham, J . C., \& Riley, J . (1998). Guidelines for treatment efficacy for young children who stutter. J ournal of SpeechLanguage-Hearing Research, 40, 753-770.

J ohnson, C., Beitchman, J ., Young, A., Escobar, M., Atkinson, L., Wilson, B., Brownlie, E., Douglas, L., Taback, N., Lam, I., \& Wang, M. (1999). F ourteen-year follow-up of children with and without speech/language impairments: Speech/language stability and outcomes. J ournal of Speech, Language, and Hearing Research, 42 744-760.

Kelly, E. (1994). Speech rates and turn-taking behaviors of children who stutter and their fathers. J ournal of Speech and Hearing Research, 37, 1284-1294.

Kelly, E., \& Conture, E. (1992). Speaking rates, responsetime latencies, and interrupting behaviors of young stutterers, nonstutterers, and their mothers. J ournal of Speech and Hearing Research, 35, 1256-1267.

Langlois, A., Hanrahan, L., \& Inouye, L. (1986). A comparison of interactions between stuttering children, nonstuttering children, and their mothers. J ournal of Fluency Disorders, 11, 263-273.

LaSalle, L., \& Conture, E. (1991). Eye contact between young stutterers and their mothers. J ournal of Fluency Disorders, 16, 173-200.

Louko, L., E dwards, M. L., \& Conture, E. (1990). Phonological characteristics of young stutterers and their normally fluent peers: Preliminary observations. J ournal of Fluency Disorders, 15, 191-210.

MacWhinney, B. (1995). The CHILDES Project. Hillsdale, $\mathrm{NJ}$ : Erlbaum.

Meyers, S., \& F reeman, F. (1985a). I nterruptions as a variable in stuttering and disfluency. J ournal of Speech and Hearing Research, 28, 428-435.

Meyers, S., \& F reeman, F. (1985b). Mother and child speech rate as a variable in stuttering and disfluency. J ournal of Speech and Hearing Research, 28, 436-444.

Murray, A., J ohnson, J ., \& Peters, J . (1990). Fine-tuning of utterance length to preverbal infants: Effects on later language development. J ournal of Child Language, 17, 511-525.

Nelson, K., Welsh, J ., Camarata, S., Butkovsky, L., \& Camarata, M. (1995). Available input for languageimpaired children and younger children of matched language levels. First Language, 43, 1-18.

Nippold, M. (1990). Concomitant speech and language disorders in stuttering children: A critique of the literature. 
J ournal of Speech and Hearing Disorders, 55, 51-60.

Nippold, M., \& Rudzinski, M. (1995). Parents' speech and children's stuttering: A critique of the literature. J ournal of Speech and Hearing Research, 38, 978-989.

Perlmann, R. (1984). Variations in socialization style: Family talk at the dinner table U npublished dissertation, Boston University.

Perlmann, R., \& Gleason, J . B. (1993). The neglected role of fathers in children's communicative development. Seminars in Speech and Language, 14, 314-324.

Quarrington, B., Seligman, J ., \& Kosower, E . (1969). Goal-setting behavior of parents of beginning stutterers and parents of nonstuttering children. J ournal of Speech and Hearing Research, 12, 435-442.

Ratner, N. B. (1988). Patterns of parental vocabulary selection in speech to young children. J ournal of Child Language, 15, 481-492.

Ratner, N. B. (1995). Language complexity and stuttering in children. Topics in Language Disorders, 15, 32-47.

Ratner, N. B. (1997). Stuttering: A psycholinguistic perspective. In R. Curlee \& G. Siegel (Eds.), Natureand treatment of stuttering: New directions ( $2^{\text {nd }} e d .$, pp. 97-127). Boston: Allyn \& Bacon.

Ratner, N. B., Rooney, B., \& MacWhinney, B. (1996). Analysis of stuttering using CHILDES and CLAN. Clinical Linguistics and Phonetics, 10, 169-187.

Robinson, B., \& Mervis, C. (1999). Comparing productive vocabulary measures from the CDI and a systematic diary study. J ournal of Child Language, 26, 177-186.

Rondal, J . (1978). Maternal speech to normal and Down's syndrome children matched for mean length of utterance. Monographs of the American Association of Mental Deficiency, 3, 193-265.

Ryan, B. (1992). Articulation, language, rate and fluency characteristics of preschool stuttering children. J ournal of Speech and Hearing Research, 35, 333-342.

Shapiro, D. (1999). Stuttering intervention: A collaborative journey to fluency freedom. Austin, TX: Pro-Ed.

Snow, C. (1986). Conversations with children. In P. Fletcher $\&$ M. Garman (Eds.), Language acquisition (2nd ed., pp. 69-89). Cambridge, U.K.: Cambridge University Press.

Snow, C. (1995). Issues in the study of input: Fine tuning, universality, individual and developmental differences, and necessary causes. In B. MacWhinney \& P. Fletcher (E ds.), The handbook of child language (pp. 180-193). Oxford, U.K.: Basil Blackwell.

Sokolov, J . (1993). A local contingency analysis of the fine-tuning hypothesis. Devel opmental Psychology, 29 1008-1023.

Starkweather, C. W. (1997). Therapy for younger children. In R. Curlee \& G. Siegel (Eds.), Nature and treatment of stuttering: New directions (2nd ed., pp. 257-279). Boston: Allyn \& Bacon.

Starkweather, C. W., Gottwald, S., \& Halfond, M. (1993). Stuttering prevention: A clinical method. Englewood Cliffs, $\mathrm{NJ}$ : Prentice-Hall.

St. Louis, K., \& Hinzman, A. (1988). A descriptive study of speech, language and hearing characteristics of school-aged stutterers. J ournal of Fluency Disorders, 13, 331- 355 .

Stephenson-Opsal, D., \& Ratner, N. B. (1988). Maternal speech rate modification and childhood stuttering. J ournal of Fluency Disorders, 13, 49-56.

Stuttering Foundation of America. (1993). Stuttering and your child (video). Memphis, TN: Stuttering Foundation of America.

Thal, D., O'Hanlon, L., Clemmons, M., \& Fralin, L. (1999). Validity of a parent report measure of vocabulary and syntax for preschool children with language impairment. J ournal of Speech, Language, and Hearing Research, 42, 482-496.

Tomasello, M., \& Mervis, C. (1994). The instrument is great, but measuring comprehension is still a problem. Monographs of the Society for Research in Child Development, 59, 174-179.

Van Riper, C. (1973). The nature of stuttering. Englewood Cliffs, NJ : Prentice-Hall.

Wall, M., \& Myers, F. (1995). Clinical management of childhood stuttering (2nd ed.). Austin, TX: Pro-Ed.

Wiig, E., Secord, W., \& Semel, E. (1992). Clinical Evaluation of Language Functions-Preschool. San Antonio, TX: Psychological Corporation.

Yairi, E. (1997). Home environments and parent-child interaction in childhood stuttering. In R. Curlee \& G. Siegel (Eds.), Nature and treatment of stuttering: New directions (2nd ed., pp. 24-48). Boston: Allyn \& Bacon.

Received August 23, 1999

Accepted March 6, 2000

Contact author: Nan Bernstein Ratner, PhD, Department of Hearing and Speech Sciences, The University of Maryland, College Park, 0100 Lefrak Hall, College Park, MD 20742. Email: nratner@hesp.umd.edu 
Appendix. Correlations between parental judgments on the SLAS and CDI and child performance, by group and parent.

\begin{tabular}{|c|c|c|c|c|c|c|c|c|c|c|}
\hline \multicolumn{11}{|c|}{ M others of stuttering children $(n=11)$} \\
\hline SLAS & $p$ & .0232 & .3569 & .1674 & .0677 & .0035 & .2188 & .0003 & .0007 & .0035 \\
\hline \multirow[t]{2}{*}{ CDI } & $r$ & .3015 & .6300 & .4477 & .4969 & .3489 & .1147 & .4709 & .4461 & .4270 \\
\hline & $p$ & .3677 & .0378 & .1674 & .1200 & .2975 & .7370 & .1438 & .1690 & .1903 \\
\hline \multicolumn{11}{|c|}{ Fathers of stuttering children $(n=8)$} \\
\hline \multirow[t]{2}{*}{ SLAS } & $r$ & .8146 & .6272 & .7869 & .6236 & .7691 & -.5780 & .6585 & .6239 & .6499 \\
\hline & $p$ & .0138 & .0960 & .0205 & .0985 & .0257 & .1134 & .0758 & .0983 & .0811 \\
\hline \multirow[t]{2}{*}{ CDI } & $r$ & .5730 & .8885 & .6158 & .6079 & .4647 & -.5953 & .6897 & .6945 & .6905 \\
\hline & $p$ & .1377 & .0032 & .1041 & .1099 & .2460 & .1134 & .0584 & .0560 & .0580 \\
\hline CDI & $p$ & .8690 & .3088 & .3960 & .1483 & .5523 & .4933 & .0962 & .1220 & .1759 \\
\hline \multicolumn{11}{|c|}{ Fathers of children who do not stutter $(n=9)$} \\
\hline \multirow[t]{2}{*}{ SLAS } & $r$ & .1908 & -.1348 & .0847 & -.0771 & .4548 & -.2294 & .4872 & .4830 & .4970 \\
\hline & & .6229 & .7296 & .8284 & .8436 & .2188 & .5526 & .1834 & .1878 & .1734 \\
\hline \multirow[t]{2}{*}{ CDI } & $r$ & .5870 & .0052 & -.0482 & -.2093 & .2322 & .2187 & -.0351 & -.0400 & .0325 \\
\hline & & .0966 & .9893 & .9019 & .5889 & .5476 & .5719 & .9286 & .9188 & .9339 \\
\hline
\end{tabular}

Note. Bolded numbers indicate correlations significant at $p<.0125$. 